\title{
Inability to process and store proinsulin in transdifferentiated pancreatic acinar cells lacking the regulated secretory pathway
}

\author{
A Alidibbiat, C E Marriott ${ }^{1}$, K T Scougall, S C Campbell, G C Huang ${ }^{2}$, W M Macfarlane ${ }^{1}$ and J A M Shaw \\ Diabetes Research Group, Institute for Cell and Molecular Biosciences, Newcastle University, Newcastle upon Tyne NE2 4HH, UK \\ ${ }^{1}$ School of Pharmacy and Biomolecular Sciences, University of Brighton, Brighton, BN2 4GJ, UK \\ ${ }^{2}$ Department of Diabetes, Endocrinology and Internal Medicine, King's College GKT Medical School, London, SE 5 9SJ, UK \\ (Correspondence should be addressed to J A M Shaw; Email: jim.shaw@newcastle.ac.uk)
}

\begin{abstract}
Generation of new $\beta$-cells from the adult pancreas or the embryonic stem cells is being pursued by research groups worldwide. Success will be dependent on confirmation of true $\beta$-cell phenotype evidenced by capacity to process and store proinsulin. The aim of these studies was to robustly determine endocrine characteristics of the AR42J rat pancreatic acinar cell line before and after in vitro transdifferentiation. $\beta$-cell phenotypic marker expression was characterised by RT-PCR, immunostaining, western blotting, ELISA and in human preproinsulin transgene over-expression studies in wild-type AR42J cells and after culture on Matrigel basement membrane matrix with and without growth/differentiation factor supplementation. Pancreatic duodenal homeobox 1 (PDX1), forkhead box transcription factor a2 (Foxa2), glucokinase, pancreatic polypeptide and low-level insulin gene transcription in wild-type AR42J cells were confirmed by RT-PCR. Culture on Matrigel-coated plates and supplementation of
\end{abstract}

medium with glucagon-like peptide 1 induced expression of the $\beta$-cell Glut 2 with maintained expression of insulin and PDX1. Increased biosynthesis and secretion of proinsulin were confirmed by immunocytochemical staining and sensitive ELISA. Absence of the regulated secretory pathway was demonstrated by undetectable prohormone convertase expression. In addition, inability to process and store endogenous proinsulin or human proinsulin translated from a constitutively over-expressed preproinsulin transgene was confirmed. The importance of robust phenotypic characterisation at the protein level in attempted $\beta$-cell transdifferentiation studies has been confirmed. Rodent and human sensitive/specific differential proinsulin/insulin ELISA in combination with human preproinsulin over-expression enables detailed elucidatation of core endocrine functions of proinsulin processing and storage in putative new $\beta$-cells.

Journal of Endocrinology (2008) 196, 33-43

\section{Introduction}

$\beta$-cell replacement therapy offers the potential of liberation from daily insulin injections with normalisation of blood glucose levels preventing significant hypoglycaemia and longterm micro-/macro-vascular complications in those with type 1 diabetes. This has been achieved through transplantation of vascularised pancreas or isolated islets retrieved from deceased donors (Shapiro et al. 2000, Robertson 2004). Widespread implementation remains severely restricted by limited donor organ availability. Generation of new $\beta$-cells from the adult pancreas or the embryonic stem cells has been sought by many groups worldwide. The need for increased rigour in defining a true $\beta$-cell phenotype has been the focus of much debate (Halban et al. 2001, Hansson et al. 2004, Weir 2004).

The phenomenon of transdifferentiation from one differentiated phenotype into another (Tosh \& Slack 2002) has been observed in a number of tissues. Examples include pancreatic cell transdifferentiation into liver cells (Tosh et al. 2002); and hepatocyte (Kojima et al. 2003) or bile duct cell transdifferentiation into pancreatic cells (Burke et al. 2004).

Generation of new insulin-secreting cells from the adult pancreas has been confirmed in vitro and in vivo. Whether these cells originate from neogenesis of progenitor or stem cells residing within the pancreas (Guz et al. 2001, Bonner-Weir \& Sharma 2002), within the bone marrow (Ianus et al. 2003) or other extrapancreatic site (Kodama et al. 2003); transdifferentiation of ductal or acinar cells (Mashima 1996, Bulotta et al. 2002, Minami et al. 2005); or selfduplication of existing $\beta$-cells (Dor et al. 2004) remains unresolved. It has been proposed that study of clonal cell lines may enable clearer elucidation of underlying physiological mechanisms (Soria et al. 2000).

The aim of the current studies was to determine the expression of key $\beta$-cell phenotypic markers in the AR42J pancreatic acinar cell line before and after $\beta$-cell transdifferentiation protocols. Ability to store and process proinsulin was specifically elucidated. 


\section{Materials and Methods}

\section{Reagents and kits}

Activin A (Act A) and hepatocyte growth factor (HGF) were purchased from Sigma-Aldrich; glucagon-like peptide 1 (7-36) (GLP1) from Bachem (Merseyside, UK) and Betacellulin (BTC) from R\&D Systems (Oxon, UK). M-MLV reverse transcriptase, oligo dTs, dNTPs and RNase-free DNase were from Promega; Red Taq polymerase from Sigma-Aldrich and Matrigel extracellular matrix from BD Bioscience (San Jose, CA, USA). RNeasy mini kits and endotoxin-free DNA extraction/purification maxiprep kits were from Qiagen. Western blotting reagents were from Amersham. Rat proinsulin, rat ultrasensitive insulin, human proinsulin and sensitive human insulin ELISA kits were from Mercodia (Uppsala, Sweden). Human intact proinsulin and human insulin ELISA kits were from DakoCytomation (Cambridgeshire, UK).

\section{Cell culture and transdifferentiation protocols}

AR42J rat acinar cell line and ARIP rat ductal cell line were obtained from ATCC (Teddington, UK). MIN6 $\beta$-cell line was available within the group. Culture media and other reagents were purchased from Sigma-Aldrich unless stated otherwise. Foetal calf serum (FCS) was from Gibco/Invitrogen Ltd. AR42J and ARIP cells were grown in Kaighn's modification of Ham's F12 Medium (F12K) containing $2 \mathrm{mM}$ L-glutamine supplemented with 20\% FCS (AR42J) or $10 \%$ FCS (ARIP), $100 \mathrm{U} / \mathrm{ml}$ penicillin and $100 \mu \mathrm{g} / \mathrm{ml}$ streptomycin. MIN6 cells were grown in Dulbecco's Modified Eagle Medium (DMEM) containing $2 \mathrm{mM}$ L-glutamine and supplemented with 15\% FCS, $100 \mathrm{U} / \mathrm{ml}$ penicillin, $100 \mu \mathrm{g} / \mathrm{ml}$ streptomycin and $0.0004 \%$ $\beta$-mercaptoethanol (v/v).

Cells were established on normal tissue culture plates (AR 42J, ARIP, MIN6) or plates coated with Matrigel (AR42J). Sterile coverslips were placed in wells prior to seeding for immunocytochemistry studies. Cells were incubated at $37^{\circ} \mathrm{C}$ under a humidified atmosphere containing $5 \% \mathrm{CO}_{2}$. When cells were near confluence they were washed twice in sterile PBS and fed with complete medium with or without $10 \mathrm{nM}$ GLP1, $2 \mathrm{nM}$ Act A, 100 pM BTC and/or 100 pM HGF. Medium was collected and replaced every $24 \mathrm{~h}$.

\section{Rat and human islet (pro)insulin content and secretion}

Rat islets were isolated from $300 \mathrm{~g}$ male Wistar rats (Charles River, Margate, UK) by collagenase P digestion of distended pancreases as previously described (Campbell \& Macfarlane 2002). Islets were hand picked and either used for total RNA extraction or pre-incubated in CMRL 1066 medium (Invitrogen) containing 5.6 mM glucose supplemented with 10\% Gold FCS (PAA, Somerset, UK), $100 \mathrm{U} / \mathrm{ml}$ penicillin, $100 \mu \mathrm{g} / \mathrm{ml}$ streptomycin and ITS-A (Invitrogen) in nonadherent flasks (Nunc, Hereford, UK) for $24 \mathrm{~h}$ at $37^{\circ} \mathrm{C}$ in a humidified $5 \% \mathrm{CO}_{2}$ incubator. Following washing with Hank's balanced salt solution (PAA, Somerset, UK), 10 sizematched islets were hand picked and cultured in CMRL 1066 medium supplemented with $0 \cdot 2 \mathrm{~g} / 1$ human serum albumin (HSA; First, Link Ltd, Birmingham, UK), $100 \mathrm{U} / \mathrm{ml}$ penicillin and $100 \mu \mathrm{g} / \mathrm{ml}$ streptomycin with six repeats. Islets were cultured at $37^{\circ} \mathrm{C}$ in a humidified $5 \% \mathrm{CO}_{2}$ incubator for $72 \mathrm{~h}$. Supernatants and islets were collected and stored at $-20{ }^{\circ} \mathrm{C}$ for later insulin determination. Islets were lysed in PBS by three cycles of freeze thawing followed by centrifugation at $13000 \mathrm{~g}$ for $5 \mathrm{~min}$. Secreted insulin in the supernatant and insulin content in the lysates were determined using high range rat insulin ELISA (Mercodia). Proinsulin content and secretion were determined by rat proinsulin ELISA (Mercodia). Total protein was determined using Bio-Rad protein assay dye reagent.

Human islets were isolated from the pancreases retrieved from heart beating deceased human donors following ethical approval and informed consent from donor relatives.

Cold ischaemic time was $<9 \mathrm{~h}$ for all the pancreases. Islets were isolated at King's College Islet Isolation Facility, London, as previously described (Huang et al. 2004). Isolated islets were transported to Newcastle University in Islet Transport Medium (CMRL 1066-Supplemented (Cellgro, Herndon, VA, USA), supplemented with 5\% HSA (w/v) (First, Link Ltd)). Islet viability was $>90 \%$ with purity $>70 \%$. (Pro)insulin content and release was determined in four groups of five size-matched islets washed with PBS and cultured at $37^{\circ} \mathrm{C}$ in a humidified $5 \%$ $\mathrm{CO}_{2}$ incubator for $24 \mathrm{~h}$ in fresh culture medium (CMRL 1066 (Gibco/Invitrogen) supplemented with 1\% HSA (w/v), $100 \mathrm{U} / \mathrm{ml}$ penicillin and $100 \mu \mathrm{g} / \mathrm{ml}$ streptomycin. Supernatants and islets were collected and stored at $-20^{\circ} \mathrm{C}$ for later insulin determination. Islets were lysed in PBS by three cycles of freeze thawing followed by centrifugation at 14000 r.p.m. for $5 \mathrm{~min}$. Insulin content and release were determined using human insulin ELISA (DakoCytomation), while proinsulin was determined by human total proinsulin ELISA (Mercodia). Total protein content was determined using Bio-Rad protein assay dye reagent.

\section{Transfection studies}

Sub-cloning of wild-type human preproinsulin cDNA (hppI1) into pIRES-neo (Clontech) to generate pIRES-hppI1 has been described (Shaw et al. 2002). An enhanced green fluorescent protein reporter cDNA (eGFP) was sub-cloned as a BamHI fragment from the plasmid pEGFP (Clontech) into the multiple cloning site of pIRES-neo to generate the control plasmid pIRES-eGFP. Plasmids were amplified in DH5 $\alpha$ sub-cloning grade Escherichia coli, purified and redissolved in endotoxin-free water at a concentration of $1 \mu \mathrm{g} / \mu \mathrm{l}$. Purity was confirmed by spectrophotometry (A260/A280 ratio 1:6-1:8) and agarose gel electrophoresis following restriction digestion.

AR42J and MIN6 cells were seeded in 6-well tissue culture plates at $8 \times 10^{4}$ cells/well. Cells at $80 \%$ confluence were washed in sterile PBS. For each well, $3 \mu \mathrm{g}$ plasmid DNA 
diluted in $100 \mu \mathrm{l}$ un-supplemented F12K/DMEM and $5 \mu \mathrm{l}$ lipofectamine 2000 diluted in $100 \mu \mathrm{l}$ un-supplemented F12K/DMEM were combined; mixed gently and incubated at room temperature for $30 \mathrm{~min}$ to allow DNA-liposome complex formation. This was added to $0.8 \mathrm{ml}$ serum-free medium and cells were incubated for $5 \mathrm{~h}$ at $37^{\circ} \mathrm{C}$ in a humid atmosphere of $5 \% \mathrm{CO}_{2}$. Transfection mix was replaced with $2 \mathrm{ml}$ complete culture medium. Medium was harvested at $24 \mathrm{~h}$ and fresh medium added. To evaluate intracellular (pro)insulin storage, cells were washed in PBS, scraped in $1 \mathrm{ml}$ PBS and lysed by three cycles of liquid nitrogen snap freezing; thawing in $37^{\circ} \mathrm{C}$ water and vortexing. Lysed cells were centrifuged at $13000 \boldsymbol{g}$ for $3 \mathrm{~min}$ to pellet cellular debris.

\section{RT-PCR}

Oligonucleotide synthesis was performed by TAGN (Gateshead, UK). Primer sequences are shown in Table 1.

RNA was extracted from cells grown as a monolayer or from hand-picked islets employing RNeasy extraction kits according to the manufacturer's protocol. All RNA samples were DNase treated. RNA was reverse transcribed using M-MLV reverse transcriptase prior to PCR $\left(5 \mathrm{~min}\right.$ at $95^{\circ} \mathrm{C}$; 29-40 cycles: $30 \mathrm{~s}$ at $95^{\circ} \mathrm{C}, 45$ s at $58^{\circ} \mathrm{C}, 45$ s at $72{ }^{\circ} \mathrm{C} ; 5$ min at $72^{\circ} \mathrm{C}$ ). PCR cycle number was 35 for all primer pairs with the exception of Isl1 (29 cycles) and forkhead box transcription factor a2 (Foxa2; 40 cycles). PCR products were separated and visualised on $1 \%$ agarose gels. DNasetreated RNA was employed in all studies as negative control.

\section{Antibodies}

Guinea pig anti-porcine insulin antibody (100\% cross-reactivity with rat insulin) was purchased from DakoCytomation. Goat antirat C-peptide antibody (100\% cross-reactivity with rat and mouse C-peptide; $<0 \cdot 1 \%$ cross-reactivity with rat insulin) was purchased from Linco. Rabbit anti-pancreatic duodenal homeobox 1 (PDX1) antibody for western blotting was a kind gift from Prof. Christopher Wright (Vanderbilt University Medical Centre, Tennessee). Mouse anti-human monoclonal pan-cytokeratin

Table 1 Primers employed in the gene expression evaluation studies

\section{Forward}

Primer: name (specificity)

PDX1 (rat)

Insulin (rat)

Foxa2 (rat)

Is/1 (rat)

GK (rat)

Glut2 (rat)

$P P$ (rat)

Glucagon (rat, human)

$P C 1 / 3$ (rat)

Amylase (rat)

$G A P D H$ (rat)

\author{
ATGAATAGTGAGGAGCAGTA \\ TGCCCAGGCTTTTTGTCAAACAGCACCTT \\ AGCCCGAGGGCTACTCTT \\ AGATATGGGAGACATGGGCGAT \\ AAGGGAACAACATCGTAGGA \\ TTAGCAACTGGGTCTGCAAT \\ TGAACAGAGGGCTCAATACGAAAC \\ GTGGCTGGATTGTTTGTAATGCTG \\ GTTGGCTGAAAGGGAAAGGGAT \\ TGGCCTTCTGGATCTTGCACTC \\ ATGGTGAAGGTCGGTGTGAAC
}

and rabbit anti-human $\alpha$-amylase antibodies were from Sigma-Aldrich. Rabbit anti-human polyclonal pancreatic polypeptide antibody was from Abcam. Goat polyclonal anti-Foxa2 antibody was from Santa Cruz Biotechnology (Santa Cruz, CA, USA). Rabbit polyclonal anti-Isl1 antibody was a kind gift from Prof. H Edlund (Umeå. University, Sweden). Texas Redconjugated secondary antibodies were from Jackson ImmunoResearch (Soham, Cambridgeshire, UK). FITC-conjugated secondary antibodies were purchased from Sigma-Aldrich. Horse radish peroxidase (HRP)-conjugated anti-rabbit and antimouse antibodies were purchased from Amersham and HRPconjugated anti-guinea pig antibodies from Sigma-Aldrich.

\section{Immunocytochemistry}

At confluence or after growth factor treatment, coverslips were removed and washed twice in PBS. Cells were fixed with $4 \%$ paraformaldehyde at $4{ }^{\circ} \mathrm{C}$ for $10 \mathrm{~min}$, and permeabilised with $0.05 \% \mathrm{v} / \mathrm{v}$ Triton $\times 100 / 0.5 \% \mathrm{w} / \mathrm{v}$ BSA for $5 \mathrm{~min}$. Nonspecific binding was blocked with blocking buffer $(6 \cdot 7 \%$ glycerol, $0 \cdot 2 \%$ Tween-20, $2 \%$ BSA in PBS) $\mathrm{pH} 7 \cdot 4$ for $30 \mathrm{~min}$. Cells were incubated with primary antibodies diluted in blocking buffer (1:150 for insulin, 1:100 for PDX1, 1:200 for amylase, 1:100 pancreatic polypeptide, 1:100 for pan-cytokeratin) for $1 \mathrm{~h}$ at room temperature or $24 \mathrm{~h}$ at $4{ }^{\circ} \mathrm{C}$ followed by four washes with wash buffer $(6 \cdot 7 \%$ glycerol, $0 \cdot 1 \%$ Tween-20, $2 \% \mathrm{BSA}$ in PBS). Cells were incubated with the appropriate secondary antibody diluted 1:300 in blocking buffer in a dark humidified chamber at room temperature for $1 \mathrm{~h}$. Following four washes, cells were mounted with Vectashield containing 4'-6-diamidino-2-phenylindole (DAPI) blue nuclear stain (Vector Laboratories Ltd, Peterborough, UK), and visualised under the Nikon Eclipse E-400 fluorescent microscope. Images were captured by Nikon digital Camera DXM1200 using Lucia DXM200 software.

\section{Western blotting}

Cells grown to confluence were harvested by scraping in PBS. Cells were pelleted by centrifugation and resuspended in
Reverse

TATGCACCTCCTGCCCACTG CTCCAGTGCCAAGGTCTGAA GCTCATCGAGTTCATGTT ACACAGCGGAAACACTCGATG CATTGGCGGTCTTCATAGTA GGTGTAGTCCTACACTCATG AGACAGAAGGGAGGCTACAAATCC CGGTTCCTCTTGGTGTTCATCAAC GAATCTTTGATGATTGCTTTGA AGGCTGACCGTTGACTACATTCCT TTACTCCTTGGAGGCCATGTA
Product size $(b p)$

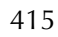

186

340

326

129

342

213

235

457

726

1003 
$400 \mu \mathrm{l}$ of $10 \mathrm{mM}$ HEPES $\mathrm{pH} 7 \cdot 9$ containing $10 \mathrm{mM} \mathrm{KCl}$, $0 \cdot 1 \mathrm{mM}$ EDTA, $0 \cdot 1 \mathrm{mM}$, EGTA, $1 \mathrm{mM}$ dithiothreitol and protease inhibitor cocktail (Roche Diagnostics Ltd). Cells were incubated on ice for $15 \mathrm{~min}$. An aliquot of $25 \mu 110 \%$ (v/v) Nonidet P-40 was added prior to 30-min incubation on ice and centrifugation. Cytoplasmic fraction (supernatant) was aliquoted and snap frozen in liquid nitrogen. Nuclear fraction (pellet) was resuspended in $50 \mu \mathrm{l}$ of $20 \mathrm{mM}$ HEPES pH 7.9 containing $10 \mathrm{mM} \mathrm{NaCl}, 1 \mathrm{mM}$ EDTA, $1 \mathrm{mM}$ EGTA, $1 \mathrm{mM}$ dithiothreitol and protease inhibitor cocktail, incubated on a rotating shaker at $4{ }^{\circ} \mathrm{C}$ for $1 \mathrm{~h}$ followed by centrifugation. Nuclear fraction (supernatant) was aliquoted and snap frozen. Protein concentration in cytoplasmic, nuclear and whole-cell extracts was quantified employing the Bradford method (Bradford 1976). On a 10\% (PDX1, Is11, Foxa2, amylase) or 15\% (insulin) SDS-acrylamide gel, $20 \mu \mathrm{g}$ protein of each sample were separated and transferred onto a nitrocellulose membrane. Membranes were blocked with $10 \% \mathrm{w} / \mathrm{v}$ non-fat milk, $1 \mathrm{M}$ Tris, $14 \cdot 6 \% \mathrm{w} / \mathrm{v} \mathrm{NaCl}$ and $0 \cdot 025 \% \mathrm{v} / \mathrm{v}$ Tween-20 for $40 \mathrm{~min}$. Membranes were incubated with PDX1 (1:5000), amylase (1:2000), Foxa2 (1:200), Isl1 $(1: 1800)$ or insulin $(1: 1000)$ antibody overnight at $4{ }^{\circ} \mathrm{C}$. Following washing with $1 \mathrm{M}$ Tris, $14 \cdot 6 \% \mathrm{w} / \mathrm{v} \mathrm{NaCl}$, $0 \cdot 025 \% \mathrm{v} / \mathrm{v}$ Tween-20 and HRP-conjugated secondary antibody (1:5000) was applied for $1 \mathrm{~h}$ at room temperature. After further washing, immuno-reactivity was detected employing a chemiluminescence kit (ECL, Amersham).

\section{(Pro)insulin ELISA}

Endogenous insulin levels were evaluated by ultrasensitive rat insulin ELISA (cross-reactivity: 100\% rat and mouse insulin (sensitivity threshold $3.5 \mathrm{pmol} / \mathrm{l}$ ), $7 \%$ rat proinsulin, $0 \cdot 001 \%$ rat C-peptide, 78\% bovine insulin; intra-assay coefficient of variation $(\mathrm{CV}): 4 \cdot 5 \%$, inter-assay $\mathrm{CV}: 2 \cdot 0 \%$; Rydgren \& Sandler 2002). Endogenous proinsulin expression was evaluated by rat proinsulin ELISA (cross-reactivity: 100\% rat and mouse proinsulin (sensitivity threshold $3 \cdot 0 \mathrm{pmol} / \mathrm{l}$ ), $<0.0007 \%$ rat C-peptide, $<0.0015 \%$ rat insulin; intra-/ inter-assay CV: 4.5\%; Leahy 1993).

Human (pro)insulin was assayed by human intact proinsulin ELISA (cross-reactivity: 100\% intact human proinsulin, 0\% human insulin, 0\% proinsulin split (32-33), 100\% proinsulin split (64-65), 0\% human C-peptide; intra-assay CV: $2 \cdot 4 \%$, inter-assay CV: 2.5\%; Luzio et al. 2001); and human insulin ELISA (cross-reactivity: 100\% human insulin, 0.01\% human proinsulin, 98\% human proinsulin des (64-65), 56\% human proinsulin split (65-66), $0 \cdot 5 \%$ human proinsulin des $(31-32)$, $0 \cdot 5 \%$ human proinsulin split (32-33); intra-assay CV: $3 \cdot 4 \%$, inter-assay CV: $3 \cdot 6 \%$; Lindstrom et al. 2002). All assays were performed according to the manufacturer's protocol.

\section{Statistical analysis}

All samples were run in triplicate. Values are expressed as mean \pm S.E.M. Values were compared employing two-tailed
Student's $t$-test using MS-Excel XP software. Results were interpreted as significant when $P$ value was $<0 \cdot 05$.

\section{Results}

\section{Characterisation of wild-type AR42J cells}

Morphology When established on uncoated tissue culture plates, the AR42J rat pancreatic acinar cell line demonstrated growth in clumps and clusters (Fig. 1a).

RT-PCR Gene expression profile in wild-type AR 42J cells in comparison to ARIP cells and primary rat islets or the MIN6 mouse $\beta$-cell line was evaluated by RT-PCR. Glyceraldehyde3-phosphate dehydrogenase (GAPDH) expression was employed as a housekeeping gene reference for all cell types (Fig. 2). Amylase expression in AR42J but not ARIP cells was confirmed. Expression at a lower level was detected in primary rat islets in keeping with the presence of contaminating acinar tissue. Expression of endocrine transcription factors (PDX1, Is11, Foxa2) and differentiated phenotypic markers (insulin, glucagon, pancreatic polypeptide (PP), glucose transporter 2 (glut2), glucokinase (GK), prohormone convertase1/3, (PC1/3) was confirmed in rat islets or MIN6 cells. Expression of PDX1 and Foxa2 in addition to PP, GK and detectable insulin at the mRNA level was demonstrated in wild-type AR42J cells. RT-PCR for Is11, Glut2 and PC1/3 was negative. Is11 and Foxa 2 expression was detected in ARIP cells but RT-PCR for all other endocrine markers was negative.

Immunocytochemistry Wild-type AR42J cells demonstrated positive staining for amylase (Fig. 1b), confirming pancreatic acinar phenotype. Amylase staining was negative in the ARIP rat ductal and MIN6 mouse $\beta$-cell lines.

False-positive staining with the polyclonal anti-porcine insulin antibody was seen in wild-type AR42J cells grown in medium supplemented with FCS. Absence of true insulin staining was, however, confirmed in definitive studies performed in serum-free medium supplemented with BSA (Fig. 3a). Positive staining was observed in MIN6 cells maintained in serum-free medium. Insulin staining was negative in ARIP cells.

Positive staining with an anti-rat C-peptide antibody with proinsulin cross-reactivity was demonstrated in $\sim 30 \%$ of wild-type AR 42J cells cultured in BSA-supplemented serumfree medium (Fig. 3b). A punctate cytoplasmic staining pattern with nuclear sparing and variable intensity between individual cells was seen. Positive C-peptide staining with comparable staining pattern was confirmed in MIN6 cells. C-peptide/proinsulin staining was negative in ARIP cells.

Pancreatic polypeptide expression with a cytoplasmic distribution was detected in wild-type AR42J cells (results not shown). Staining was negative in ARIP cells. Positive C-peptide and pancreatic polypeptide staining without co-localisation were confirmed on single cell cytospin 

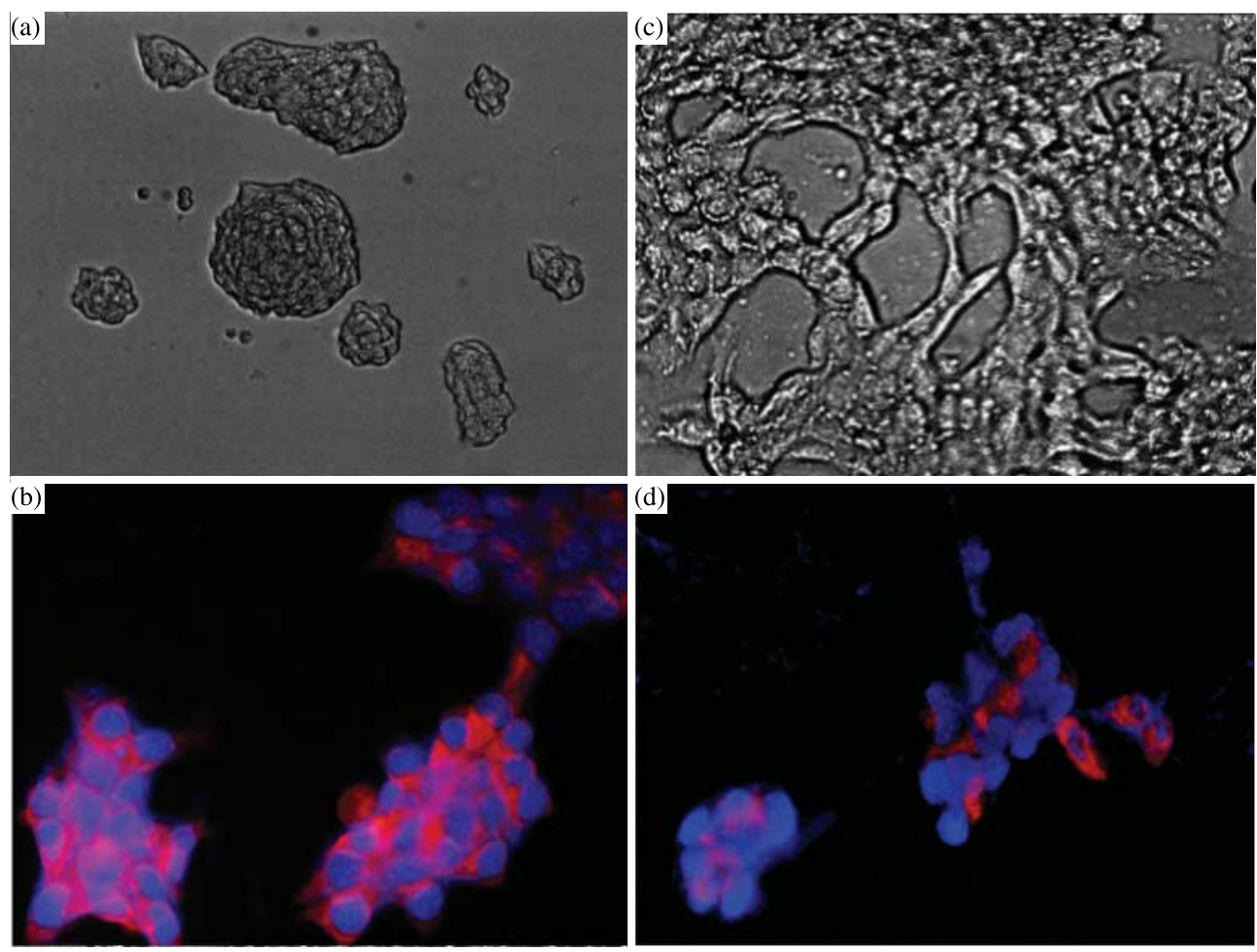

Figure 1 Morphology and exocrine immunocytochemical staining of AR42J cells grown on uncoated (a, b) or Matrigel-coated (c, d) tissue culture plates. Wild-type cells demonstrated clump and cluster growth pattern (a) with positive amylase staining in all cells (b). On Matrigel, AR42J cells showed a morphological shift towards a more flattened pattern of growth and formation of cytoplasmic extensions (c) with reduction in number of cells positive for amylase (d). Anti-amylase antibody was detected with Texas Red-conjugated secondary antibody.

preparations of rat islets confirming specificity of the antibodies (results not shown).

Western blot/ELISA Amylase protein biosynthesis in AR 42J cells was demonstrated by western blotting confirming acinar phenotype but was absent in ARIP and MIN6 cell extracts.

There was no detectable expression of mature insulin in wildtype AR42J cells grown in serum-free medium by western blotting employing the insulin-specific antibody employed in the above immunocytochemical staining studies (Fig. 4). Expression of insulin $(6 \mathrm{kDa})$ was confirmed in MIN6 cell extracts. No extra band at $9 \mathrm{kDa}$ was observed in keeping with absence of antibody cross-reactivity with proinsulin.

Expression of PDX1 protein was detectable in the nuclear MIN6 cell extracts only and not in AR42J or ARIP cells (Fig. 4). Presence of Is11 within the nucleus of MIN6 and ARIP but not AR42J cells was confirmed. Foxa2 could be detected in the nuclear extract of both AR 42J cells and MIN6 cells but not in ARIP cells.

\section{Transdifferentiation studies}

Morphology/immunocytochemistry Following establishment on Matrigel-coated plates, AR42J cells demonstrated, within $24 \mathrm{~h}$, a morphological shift with overall flattening and cytoplasmic extensions (Fig. 1c). Cells grew as an adherent monolayer with increased growth rate in comparison to cells grown on uncoated tissue culture plates. Incubation for up to 4 days in medium supplemented with a range of growth and differentiation factors (Act A, HGF, BTC, GLP1) individually or in combination did not affect morphology of cells grown on uncoated or Matrigel-coated plates. Following culture on Matrigel (Fig. 1d) and treatment with growth and differentiation factors, there was a reduction in number and intensity of amylase positive cells. C-peptide/proinsulin staining continued to be positive following culture on Matrigel with an increase in number of positive cells to $\sim 80 \%$ (Fig. 3d) but staining for insulin remained negative (Fig. 3c). No further changes in proteinlevel expression profiles were observed with addition of all tested growth and differentiation factors individually and in combination. Increased numbers of apoptotic cells were seen in all regimens including Act A.

RT-PCR Induction of Glut2 mRNA and upregulation of insulin expression (as determined by semi-quantitative RT-PCR in comparison to GAPDH housekeeping gene expression) was demonstrated in AR42J cells cultured on Matrigel (Fig. 5). Further upregulation of insulin, Glut2 and PDX1 gene expression with maintained GK expression was seen on 


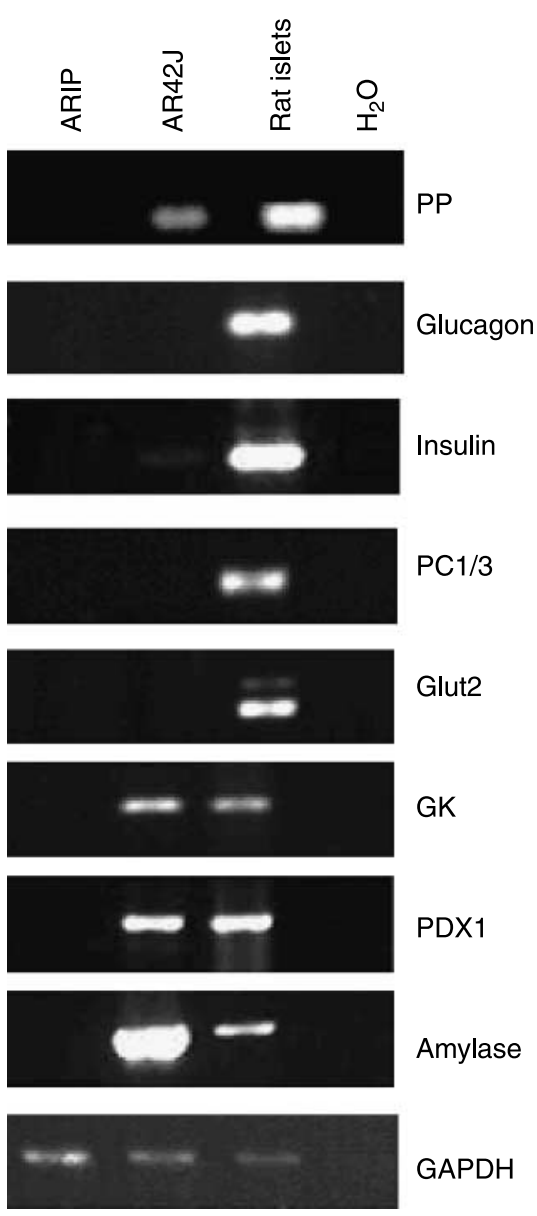

Figure 2 RT-PCR gene expression profile in wild-type AR42J cells, ARIP cells, primary rat islets and MIN6 cells. Amylase expression in AR42J and not ARIP cells was confirmed. Expression at a lower level was detected in primary rat islets in keeping with contaminating acinar tissue. Expression of all endocrine markers (PDX1, Glut2, glucokinase (GK), PC1/3, insulin, glucagon, pancreatic polypeptide (PP), Foxa2, Isl1) was confirmed in rat islets or MIN6 cells. Expression of PDX1, Foxa2, PP, GK and very low detectable insulin at the mRNA level was demonstrated in wild-type AR42J cells. Negative control represents PCR performed in the absence of cDNA.

supplementation of cells cultured on Matrigel with GLP1. Addition of BTC or HGF did not further affect gene expression profile. Addition of Act A attenuated expression of insulin, PDX1 and Glut2. PC1/3 remained undetectable under all conditions.

\section{Assay for endogenous (pro)insulin biosynthesis by}

ELISA Insulin biosynthesis and secretion was assessed in AR42J cells in comparison to MIN6 $\beta$-cells and ARIP pancreatic ductal cells by sensitive and specific rat/mouse insulin and proinsulin ELISAs of medium (collected after a 24-h incubation) and cell lysates harvested at confluence. In initial studies in AR42J cells grown in medium containing FCS, low variable insulin levels were detectable in both medium and cell lysates (0-10 pmol/1). Comparable levels were detected in ARIP cells despite absence of detectable insulin expression by RT-PCR or C-peptide by immunocytochemical staining. Moreover, equivalent levels of insulin were detected in growth medium in the absence of cells confirming assay cross-reactivity with bovine insulin within FCS. In definitive studies performed in serum-free medium supplemented with $0 \cdot 4 \%$ BSA, no fully processed insulin could be detected in AR42J cells grown on uncoated or Matrigel-coated tissue culture plates in cell medium (Fig. 6a) or lysates with or without treatment with all growth/differentiation factors. Absence of detectable insulin in ARIP cells was confirmed (Fig. 6a). In MIN6 cells cultured in BSAsupplemented serum-free medium, high levels of endogenous insulin secretion and storage were confirmed (Fig. 6b). Proinsulin biosynthesis by AR42J cells grown in BSAsupplemented serum-free medium was determined by rat-specific proinsulin ELISA. Very low but consistently detectable levels of endogenous proinsulin were secreted into medium by wild-type AR42J cells (Fig. 6a). A significant threefold increase in endogenous proinsulin secretion was detected when AR42J cells were cultured on Matrigel (Fig. 6a). No proinsulin was detected in ARIP samples in 

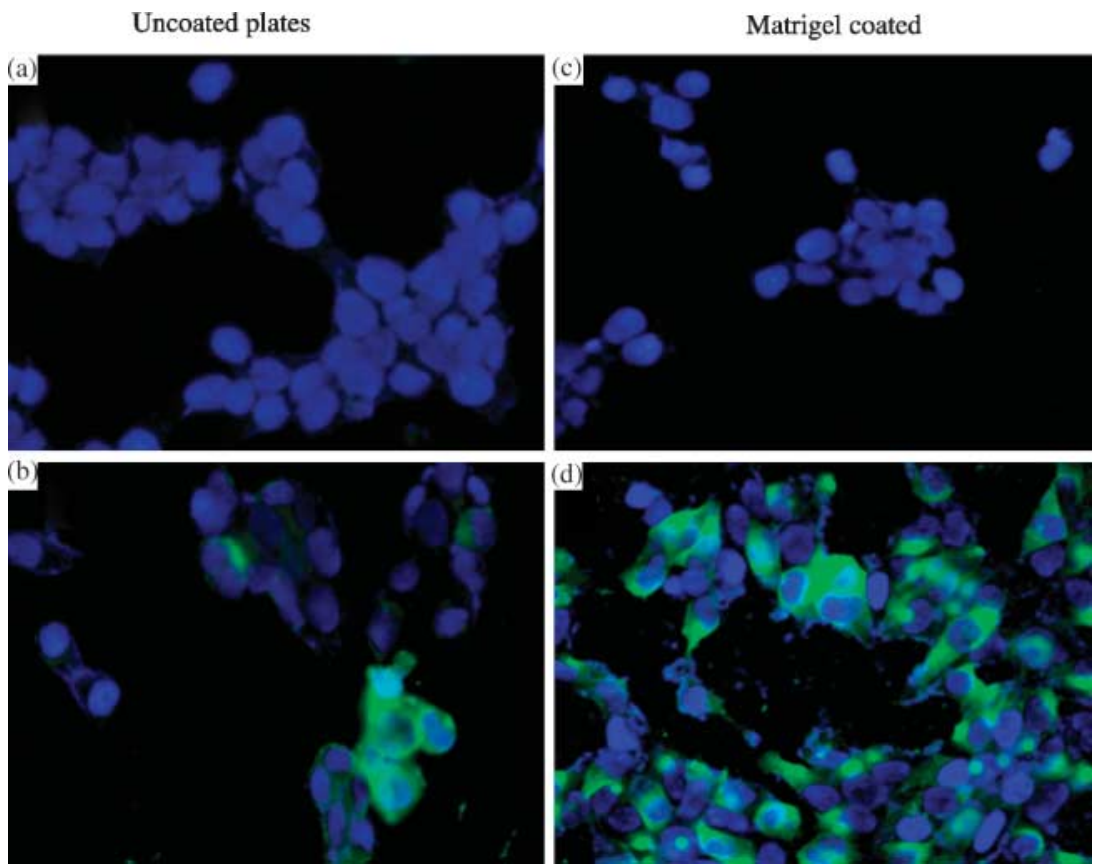

Figure 3 Endocrine immunocytochemical staining of AR42J cells grown on uncoated ( $a$ and b) or Matrigel-coated (c and d) tissue culture plates. No insulin staining was observed in wild-type AR42J cells (a) or cells grown on Matrigel in serum-free medium (c). Variable staining intensity of C-peptide was observed in a proportion of wild-type AR42J cells (b) with a marked increase in number and intensity in AR42J cells grown on Matrigel (d). Anti-insulin and anti-C-peptide antibodies were detected with FITC-conjugated secondary antibodies.

keeping with absence of proinsulin demonstrated by RT-PCR. Storage and secretion of unprocessed proinsulin were confirmed in MIN6 cells (Fig. 6b). Insulin:proinsulin ratio, however, demonstrated $>85 \%$ processing to mature insulin. In isolated rat islets, $>95 \%$ processing to mature insulin was confirmed in medium and cell lysates (Fig. 7a).

\section{Transfection with wild-type human (pro)insulin cDNA}

To further characterise endocrine phenotype in AR42J cells in comparison to MIN6 $\beta$-cells, the potential for proinsulin storage and processing was assessed in over-expression studies employing a human preproinsulin plasmid. This included the endogenous signal peptide sequence targeting newly biosynthesised peptide to the endoplasmic reticulum. Secretion by the constitutive secretory pathway without significant intracellular storage or post-translational processing to insulin has been confirmed following transient transfection of a range of non-endocrine cells lacking the regulated secretory pathway (Shaw et al. 2002, Scougall et al. 2003). Quantitative assessment of processing is enabled by sensitive and specific ELISAs for human intact proinsulin and mature fully processed insulin (Scougall \& Shaw 2003, Wilson et al. 2005).

Assay specificity was confirmed in isolated human islets demonstrating $\geq 85 \%$ processing of proinsulin into mature insulin in medium and lysates (Fig. 7b).

AR42J cells grown on uncoated or Matrigel-coated plates were transiently transfected with a wild-type human preproinsulin cDNA (hppI1) downstream of a constitutive CMV promoter in the pIRES-hppI1 plasmid employing Lipofectamine. Secretion and intracellular storage of human proinsulin and mature insulin were determined by specific ELISA of medium and cell lysate.

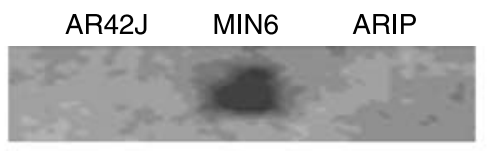

Insulin

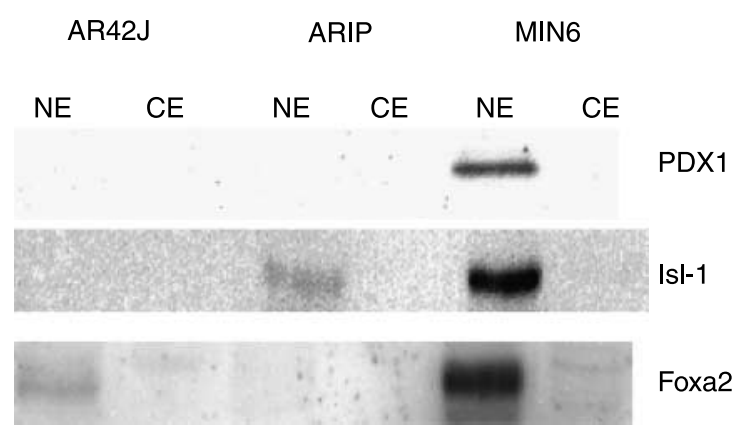

Figure 4 Western blotting for insulin, PDX1, IsI1 and Foxa2. Insulin protein expression was confirmed in MIN6 cell extracts but not in AR42J or ARIP cells. Expression of PDX1 protein was detectable in the nuclear extract (NE) of MIN6 cells but was absent in AR42J and ARIP cell nuclear and cytoplasmic extract (CE). Isl1 protein expression was detectable in both the nuclear extracts of ARIP and MIN6 cells but not in AR42J cells. Foxa2 protein was detectable in AR42J nuclear extract as well as in MIN6 nuclear extract. 


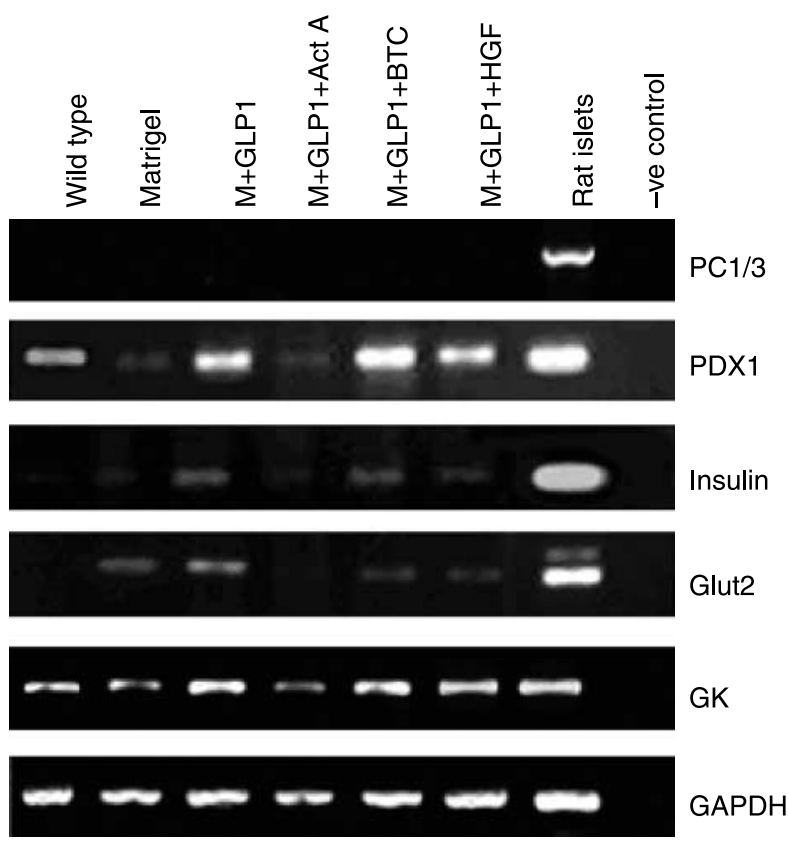

Figure 5 RT-PCR expression profiles following culture of AR42J cells on Matrigel $(\mathrm{M})$ and growth/differentiation factor treatment. Induction of Glut2 mRNA expression and maintenance of insulin expression were demonstrated on Matrigel. Supplementation with GLP-1 resulted in enhanced Glut2, PDX1 and insulin expression. Addition of Act A attenuated Glut2, PDX1 and insulin expression. BTC and HGF 1 did not further affect mRNA expression profile.

Transgene expression and significant proinsulin secretion peaking at $48-\mathrm{h}$ post-transfection were confirmed in all studies. Processing to mature insulin was minimal $(<5 \%)$ with no evidence for substantive intracellular (pro)insulin storage $(<10 \%$ of total extracellular + intracellular (pro)insulin). Processing and storage were not increased by $72-\mathrm{h}$ incubation in optimal transdifferentiation conditions: GLP1 supplementation of AR42J cells established on Matrigelcoated plates (Fig. 8a). Human proinsulin and insulin were undetectable in control untransfected cells.

In comparative human preproinsulin over-expression studies in MIN6 cells, significant processing to mature insulin and intracellular storage was confirmed (Fig. 8b). Totally $90 \%$ of intracellular human (pro)insulin was fully processed. Moreover, substantive storage of mature human insulin was confirmed. Absence of significant human insulin assay crossreactivity with endogenous murine insulin was confirmed by undetectable insulin in comparable control enhanced green fluorescent protein (eGFP) reporter gene transfections (Fig. 8b). Endogenous murine (pro)insulin cross-reactivity in the intact human proinsulin ELISA was detected in control eGFP transfections in MIN6 cells with pIRES-eGFP (Fig. 8b). This was at a low level and did not affect study interpretation. (a)
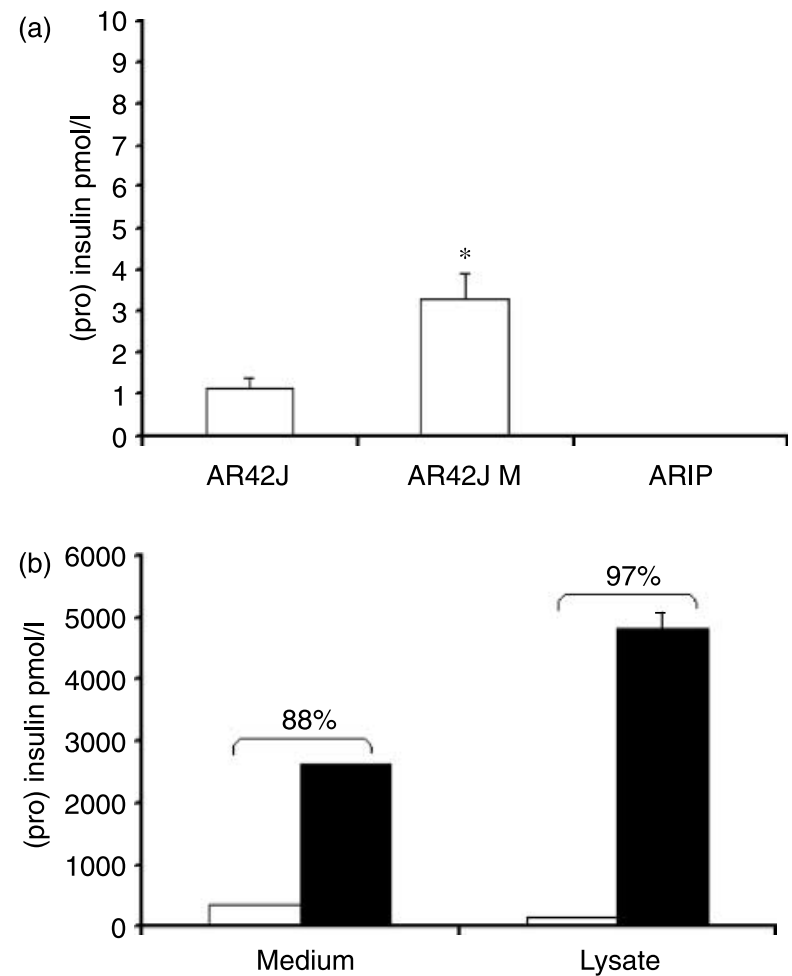

Figure 6 Secretion of rodent proinsulin (white bars) and processed insulin (black bars) in AR42J, ARIP and MIN6 cells. (a) Secretion of proinsulin but not insulin was detected from wild-type AR42J cells with an increase on culture on Matrigel $(M)$. Absence of proinsulin biosynthesis was confirmed in ARIP cells $\left(n=3 \pm\right.$ S.E.M.; ${ }^{*} P<0 \cdot 05$ versus wild-type AR42J cells). (b) Secretion/storage of proinsulin and insulin by MIN6 cells. Percentages represent percentage processing of proinsulin to insulin ( $n=3 \pm$ S.E.M).

\section{Discussion}

In these studies, expression of the insulin gene in addition to PDX1, Foxa2, PP and GK has been confirmed in the unmodified AR42J pancreatic acinar cell line. Proinsulin biosynthesis has been demonstrated by immunocytochemical staining in $\sim 30 \%$ of cells with a C-peptide antibody and by specific rat proinsulin ELISA. Absence of the regulated secretory pathway necessary for post-translational processing and storage of proinsulin was shown by negative prohormone convertase RT-PCR. This accounted for absent immunocytochemical staining with an antibody raised against mature insulin and undetectable insulin by specific rat insulin ELISA. Culture on Matrigel and medium supplementation with GLP1 induced Glut2 with maintained insulin, PDX1 and GK expression but absence of prohormone convertase mRNA expression. Increase in number of cells biosynthesising proinsulin was demonstrated by C-peptide/proinsulin immunocytochemical staining in addition to a threefold increase in secreted proinsulin. Proinsulin concentration, however, remained extremely low with no evidence of processing and storage of mature insulin by 

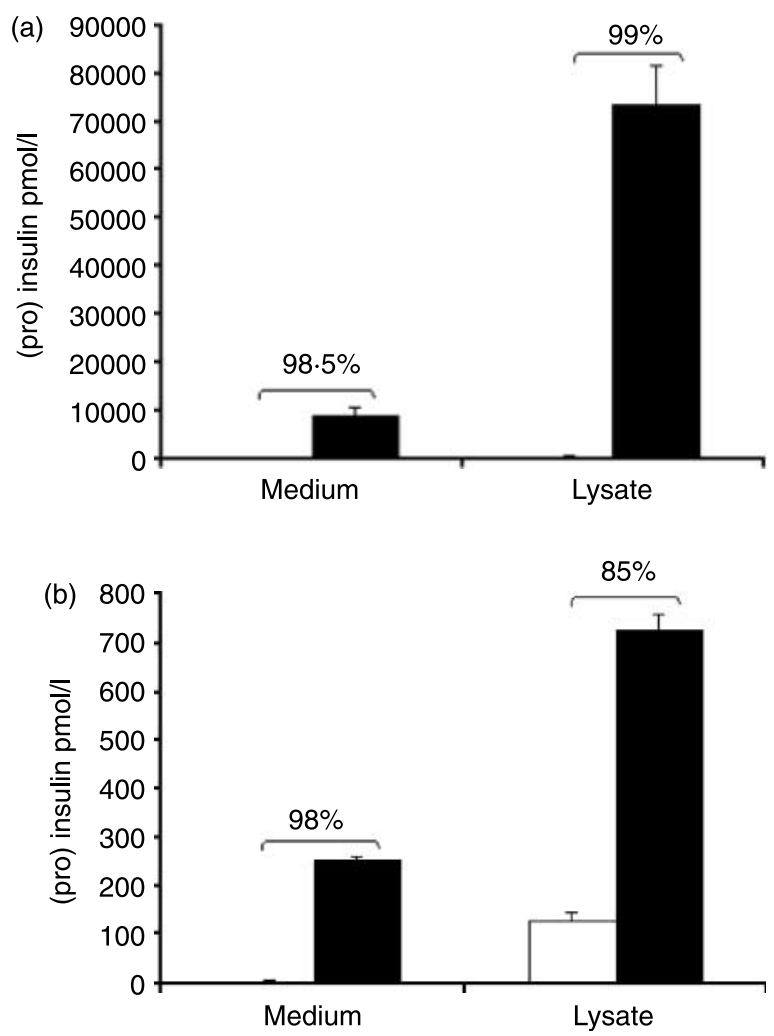

Figure 7 Secretion/storage of proinsulin and insulin in intact rat (a) and human (b) islets. (a) Rat proinsulin (white bars) and mature insulin (black bars) in medium and cell lysate after 72-h incubation. Islets were cultured in control CMRL medium (5.6 mM D-glucose) with 10 islets per group $(n=6 \pm$ S.E.M). This confirmed $>98 \%$ processing of proinsulin into mature insulin. (b) Human proinsulin (white bars) and mature insulin (black bars) in medium and cell lysate after 24-h incubation. Islets were cultured in control CMRL medium (5.6 mM D-glucose) with five islets per group ( $n=4 \pm$ S.E.M). This confirmed $\geq 85 \%$ processing of proinsulin into mature insulin.

immunostaining/specific ELISA. Inability of wild-type cells or cells treated with $\beta$-cell transdifferentiation protocols to process or store biosynthesised proinsulin was confirmed by ELISA following human preproinsulin transgenic over-expression.

The AR 42J cell line was originally derived from a chemically induced rat pancreatic carcinoma. It has been widely employed as a model for pancreatic transdifferentiation (Mashima et al. 1996, Tosh \& Slack 2002, Shen et al. 2003). Published data concerning both endocrine marker expression in wild-type cells and degree of endocrine differentiation following attempted in vitro transdifferentiation protocols are conflicting (Mashima et al. 1996, Zhou et al. 1999, Palgi et al. 2000).

Glucokinase expression but absence of PP and insulin was seen in early studies (Mashima et al. 1996). PDX1 mRNA expression has been previously reported in the AR42J B13 sub-clone (Palgi et al. 2000). Other groups have not detected expression of any endocrine markers in wild-type AR 42J cells (Silver \& Yao 2001). Establishment of AR42J cells on plates (a)

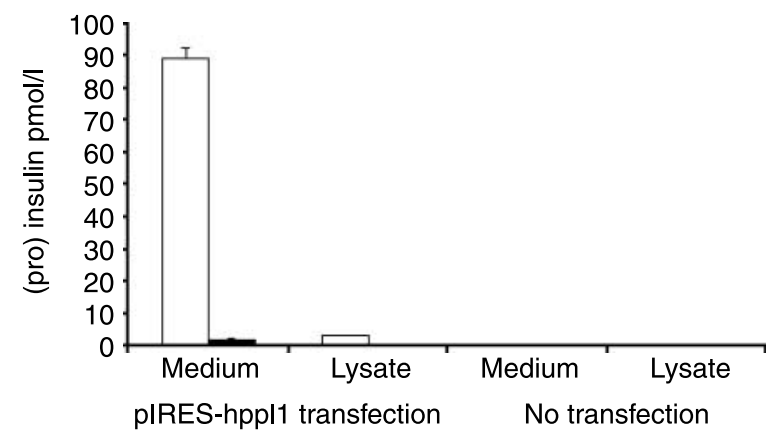

(b)

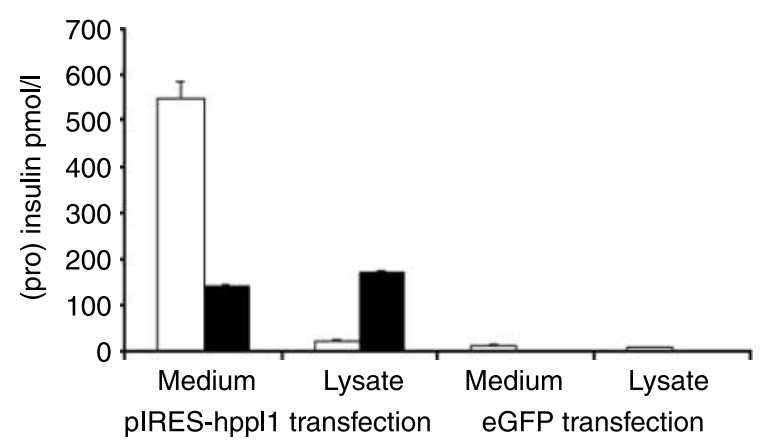

Figure 8 Human (pro)insulin biosynthesis, processing, storage and secretion in AR42J and MIN6 cells expressing wild-type human preproinsulin cDNA (pIRES-hppl1). (a) Intact human proinsulin (white bars) and mature insulin (black bars) in medium and cell lysate at 48-h post-transfection of AR42J cells established on Matrigel-coated plates and maintained in GLP-1 supplemented medium ( $n=3 \pm$ S.E.M). Processing to mature insulin was minimal $(<5 \%)$ with no evidence for substantive intracellular (pro)insulin storage ( $<10 \%$ of total extracellular + intracellular (pro)insulin). Absence of human (pro)insulin in untransfected cells was confirmed. (b) Intact human proinsulin (white bars) and mature insulin (black bars) in medium and cell lysate at 48-h posttransfection of MIN6 cells established on uncoated plates in standard medium ( $n=3 \pm$ S.E.M). Significant processing to mature human insulin and intracellular storage was confirmed. Totally $90 \%$ of intracellular human (pro)insulin was fully processed. Intracellular levels of mature human insulin were greater than levels in surrounding medium. Control transfections were performed with the pIRES-eGFP reporter gene.

pre-coated with a growth factor-enriched collagen matrix (Matrigel) induced a morphological shift with formation of neurone-like extensions. A comparable morphological shift has been described in wild-type AR42J cells (Mashima et al. 1996) in addition to the B13 sub-clone (Palgi et al. 2000) in response to Act $A$ treatment, a member of the transforming growth factor- $\beta$ family with a postulated role in pancreatic $\beta$-cell differentiation. In our studies, incubation of cells with a range of growth and differentiation factors in the absence of Matrigel did not result in a morphological shift. Act A was, however, associated with previously reported increased cell death (Zhang et al. 1999). 
Matrigel-induced morphological shift was accompanied by induction of the $\beta$-cell-specific Glut 2 with increased proinsulin secretion. Transdifferentiation of AR42J cells into insulinexpressing cells has previously been attained following treatment with GLP1 without any accompanying morphological change (Zhou et al. 1999). Induction of insulin, PP and Glut2 in the B13 subclone has been described following treatment with Act $\mathrm{A}$ in combination with either BTC or HGF, factors believed to promote growth and differentiation of pancreatic $\beta$-cells (Mashima 1996, Mashima et al. 1996), although another group was unable to replicate these findings (Palgi et al. 2000).

The possibility for insulin uptake from surrounding medium leading to false-positive insulin immunocytochemical staining has been reported in studies of attempted endocrine differentiation from embryonic stem cells (Rajagopal et al. 2003, Hansson et al. 2004). The potential for true staining with an antibody raised against insulin or C-peptide to be a marker of proinsulin biosynthesis without necessarily confirming processing to mature insulin is less well described, however. In the current studies, positive staining with a C-peptide antibody detecting proinsulin was seen, with negative staining and western blot results with an antibody specific for fully processed insulin.

Presence of FCS may be a further confounding factor in studies reporting induction of a $\beta$-cell phenotype manifest by low insulin levels detected by immunoassay (Lumelsky et al. 2001, Hansson et al. 2004). Indeed, all currently available RIA and ELISA antibodies for mouse and rat insulin appear to demonstrate high cross-reactivity with bovine insulin. False positivity was confirmed in the present studies prior to definitive experiments in which FCS was replaced with BSA.

In the present studies, a novel sensitive and specific rodent proinsulin ELISA proved extremely valuable in demonstrating secretion of proinsulin without post-translational processing in AR42J cells. Despite a threefold increase in AR42J cells cultured on Matrigel, the level of endogenous proinsulin secretion remained extremely low following all transdifferentiation protocols. Indeed, levels were too low for meaningful processing and storage analysis.

Regardless of overall level of hormone synthesis, expression of the regulated secretory pathway is a defining characteristic of a true endocrine cell. This pathway is necessary for prohormone processing through expression of the specific endoproteases PC1/3 and PC2; intracellular storage of preformed hormone and rapid calcium-gated secretion. In the current studies, PC1/3 expression was not detected in AR42J cells before or after any of the transdifferentiation protocols. Constitutive expression of a wild-type human preproinsulin cDNA led to constitutive proinsulin secretion confirming the inability of wild-type or transdifferentiated AR42J cells to process or store proinsulin. In contrast, transfected MIN6 $\beta$-cells demonstrated significant post-translational processing of human proinsulin to mature insulin in addition to a high level of intracellular human insulin storage. This approach enables utilisation of highly sensitive and specific human ELISAs precluding false-positivity arising from FCS crossreactivity in murine ELISAs.
In conclusion, the potential for transdifferentiation of rat acinar AR42J cells towards an endocrine phenotype in vitro has been evaluated. Induction of the key $\beta$-cell markers PDX1, Glut2 and insulin at the mRNA level has been demonstrated with decreased amylase and increased proinsulin biosynthesis. Transdifferentiated cells, however, lacked the regulatory secretory pathway and were thus unable to process and store endogenous or transgenically overexpressed proinsulin. Extreme caution should be adopted in interpretation of studies reporting induction of a differentiated $\beta$-cell phenotype. Detailed (pro)insulin analysis at the protein level is mandatory. Human proinsulin over-expression provides a novel tool for robust phenotypic characterisation.

\section{Acknowledgements}

A A was supported by an Aga Khan Foundation Scholarship. C E M was supported by a studentship from the BBSRC. S C C was supported by the Newcastle upon Tyne NHS Hospitals Trust. J A M S was supported by an unrestricted GlaxoSmithKline Senior Clinical Fellowship. The authors confirm that they have no conflicts of interest that would prejudice the impartiality of this manuscript.

\section{References}

Bonner-Weir S \& Sharma A 2002 Pancreatic stem cells. Journal of Pathology 197 519-526.

Bradford MM 1976 A rapid and sensitive method for the quantitation of microgram quantities of protein utilizing the principle of protein-dye binding. Analytical Biochemistry 72 248-254.

Bulotta A, Hui H, Anastasi E, Bertolotto C, Boros LG, Di Mario U \& Perfetti R 2002 Cultured pancreatic ductal cells undergo cell cycle re-distribution and beta-cell-like differentiation in response to glucagon-like peptide-1. Journal of Molecular Endocrinology 29 347-360.

Burke ZD, Shen CN \& Tosh D 2004 Bile ducts as a source of pancreatic beta cells. BioEssays 26 932-937.

Campbell SC \& Macfarlane WM 2002 Regulation of the pdx1 gene promoter in pancreatic beta-cells. Biochemical and Biophysical Research Communications 299 277-284.

Dor Y, Brown J, Martinez OI \& Melton DA 2004 Adult pancreatic beta-cells are formed by self-duplication rather than stem-cell differentiation. Nature 429 41-46.

Guz Y, Nasir I \& Teitelman G 2001 Regeneration of pancreatic beta cells from intra-islet precursor cells in an experimental model of diabetes. Endocrinology 142 4956-4968.

Halban PA, Kahn SE, Lernmark A \& Rhodes CJ 2001 Gene and cellreplacement therapy in the treatment of type 1 diabetes: how high must the standards be set? Diabetes 50 2181-2191.

Hansson M, Tonning A, Frandsen U, Petri A, Rajagopal J, Englund MC, Heller RS, Hakansson J, Fleckner J, Skold HN et al. 2004 Artifactual insulin release from differentiated embryonic stem cells. Diabetes 53 2603-2609.

Huang GC, Zhao M, Jones P, Persaud S, Ramracheya R, Lobner K, Christie MR, Banga JP, Peakman M, Sirinivsan P et al. 2004 The development of new density gradient media for purifying human islets and islet-quality assessments. Transplantation 77 143-145.

Ianus A, Holz GG, Theise ND \& Hussain MA 2003 In vivo derivation of glucose-competent pancreatic endocrine cells from bone marrow without evidence of cell fusion. Journal of Clinical Investigation 111 843-850. 
Kodama S, Kuhtreiber W, Fujimura S, Dale EA \& Faustman DL 2003 Islet regeneration during the reversal of autoimmune diabetes in NOD mice. Science 302 1223-1227.

Kojima H, Fujimiya M, Matsumura K, Younan P, Imaeda H, Maeda M \& Chan L 2003 NeuroD-betacellulin gene therapy induces islet neogenesis in the liver and reverses diabetes in mice. Nature Medicine 9 596-603.

Leahy JL 1993 Increased proinsulin/insulin ratio in pancreas extracts of hyperglycemic rats. Diabetes 42 22-27.

Lindstrom T, Hedman CA \& Arnqvist HJ 2002 Use of a novel doubleantibody technique to describe the pharmacokinetics of rapid-acting insulin analogs. Diabetes Care 25 1049-1054.

Lumelsky N, Blondel O, Laeng P, Velasco I, Ravin R \& McKay R 2001 Differentiation of embryonic stem cells to insulin-secreting structures similar to pancreatic islets. Science 292 1389-1394.

Luzio SD, Lucas I \& Owens DR 2001 Importance of validation of immunoassays for intact proinsulin. Clinical Chemistry and Laboratory Medicine 39 631-633.

Mashima H, Shibata H, Mine T \& Hojima I 1996 Formation of insulin producing cells from pancreatic acinar AR42J cells by hepatocyte growth factor. Endocrinology 137 3969-3976.

Mashima H, Ohnishi H, Wakabayashi K, Mine T, Miyagawa J, Hanafusa T, Seno M, Yamada H \& Kojima I 1996 Betacellulin and activin A coordinately convert amylase-secreting pancreatic AR 42J cells into insulinsecreting cells. Journal of Clinical Investigation 97 1647-1654.

Minami K, Okuno M, Miyawaki K, Okumachi A, Ishizaki K, Oyama K, Kawaguchi M, Ishizuka N, Iwanaga T \& Seino S 2005 Lineage tracing and characterization of insulin-secreting cells generated from adult pancreatic acinar cells. PNAS 102 15116-15121.

Palgi J, Stumpf E \& Otonkoski T 2000 Transcription factor expression and hormone production in pancreatic AR42J cells. Molecular and Cellular Endocrinology 165 41-49.

Rajagopal J, Anderson WJ, Kume S, Martinez OI \& Melton DA 2003 Insulin staining of ES cell progeny from insulin uptake. Science 299363.

Robertson RP 2004 Consequences on beta-cell function and reserve after long-term pancreas transplantation. Diabetes 53 633-644.

Rydgren T \& Sandler S 2002 Efficacy of 1400 W, a novel inhibitor of inducible nitric oxide synthase, in preventing interleukin-1beta-induced suppression of pancreatic islet function in vitro and multiple low-dose streptozotocin-induced diabetes in vivo. European Journal of Endocrinology 147 543-551.

Scougall KT \& Shaw JA 2003 Tetracycline-regulated secretion of human insulin in transfected primary myoblasts. Biochemical and Biophysical Research Communications 304 167-175.
Scougall KT, Maltin CA \& Shaw JA 2003 Tetracycline-regulated secretion of human insulin in a transfected non-endocrine cell line. Journal of Molecular Endocrinology 30 331-346.

Shapiro AM, Lakey JR, Ryan EA, Korbutt GS, Toth E, Warnock GL, Kneteman NM \& Rajotte RV 2000 Islet transplantation in seven patients with type 1 diabetes mellitus using a glucocorticoid-free immunosuppressive regimen. New England Journal of Medicine 343 230-238.

Shaw JA, Delday MI, Hart AW, Docherty HM, Maltin CA \& Docherty K 2002 Secretion of bioactive human insulin following plasmid-mediated gene transfer to non-neuroendocrine cell lines, primary cultures and rat skeletal muscle in vivo. Journal of Endocrinology 172 653-672.

Shen CN, Horb ME, Slack JM \& Tosh D 2003 Transdifferentiation of pancreas to liver. Mechanisms of Development 120 107-116.

Silver K \& Yao F 2001 ARIP cells as a model for pancreatic beta cell growth and development. Pancreas 22 141-147.

Soria B, Andreu E, Berna G, Fuentes E, Gil A, Leon-Quinto T, Martin F, Montanya E, Nadal A, Reig JA et al. 2000 Engineering pancreatic islets. Pflugers Archiv 440 1-18.

Tosh D \& Slack JM 2002 How cells change their phenotype. Nature Reviews. Molecular Cell Biology 3 187-194.

Tosh D, Shen CN \& Slack JM 2002 Conversion of pancreatic cells to hepatocytes. Biochemical Society Transactions 30 51-55.

Weir GC 2004 Can we make surrogate beta-cells better than the original? Seminars in Cell and Developmental Biology 15 347-357.

Wilson MO, Scougall KT, Ratanamart J, McIntyre EA \& Shaw JA 2005 Tetracycline-regulated secretion of human (pro)insulin following plasmidmediated transfection of human muscle. Journal of Molecular Endocrinology 34 391-403.

Zhang YQ, Kanzaki M, Furukawa M, Shibata H, Ozeki M \& Kojima I 1999 Involvement of Smad proteins in the differentiation of pancreatic AR42J cells induced by activin A. Diabetologia 42 719-727.

Zhou J, Wang X, Pineyro MA \& Egan JM 1999 Glucagon-like peptide 1 and exendin-4 convert pancreatic AR 42J cells into glucagon- and insulinproducing cells. Diabetes 48 2358-2366.

Received in final form 9 October 2007

Accepted 17 October 2007

Made available online as an Accepted Preprint 17 October 2007 